\title{
To Estimate Prevalence of Hyperglycemia among Employees of Bell Metal Industries of Sarthebari,
} Assam

\author{
Padmaja Barua, Jolly Bhattacharjya, Smriti Pathak Dutta
}

\begin{abstract}
Noise is an environmental pollutant and in many occupational fields noise emerges as an occupational hazard. Over and above creating hearing problem, noise is found to affect other systems like cardiovascular system and metabolism. Some researchers noticed increased blood sugar level in subjects with history of noise exposure. So present study was aimed at finding out the prevalence of hyperglycemia in the employees of bell metal industries of Sarthebari, Assam. A total of 163 workers in the age group of 18-62 were included in the study. They had history of noise exposure for a duration varying from 1-21 yrs. After recording height, weight, pulse and blood pressure, the random blood sugar was measured and the variables were analyzed statistically. Using Pearson correlation coefficient age of the employees was not found to be strongly related with RBS and work duration was also not found to be strongly correlated with RBS. Using $Z$ test of proportion in our study $Z=-1.53341$, it was concluded that there was no significant prevalence of hyperglycemia among the employees of bell metal industries of Sarthebari. Further studies are needed in this field and estimation of FBS and PPBS would be more relevant to comment on hyperglycemia.
\end{abstract}

Keywords: Noise, hyperglycemia

\section{Introduction}

Noise is excessively loud undesirable sound that has deleterious effect on health. It not only leads to hearing loss but also exerts harmful impact on other systems. In various industries the employees are exposed to noise and this occupational hazard imparts negative effect on health of them. Previous study says that "persistent chronic noise exposure increases the risk of cardio metabolic diseases including arterial hypertension, CAD, DM type-II and stroke" (1). Another study says that " occupational noise exposure may be associated with an increased incidence of hyperglycemia, with the highest risk observed at $31.5 \mathrm{~Hz}$. (2) Again a study aimed at studying the effect of noise on hypertension and hyperglycemia among occupational workers, concluded that "noise exposure may increase blood pressure and blood sugar of occupational workers"(3) Sarthebari, a place of Assam in Bajali district is famous for the age old bell metal industries present here. At present there are about 320 industries and 2000 employees. This second largest handicraft of Assam involves production of noise due to hammering of metal. So the employees of these bell metal industries are chronically exposed to noise. But unfortunately health studies are lacking in this region. So this study design aims at estimating the prevalence of hyperglycemia among employees of bell metal industries of Sarthebari.

\section{Materials and methods}

Study design- Descriptive cross sectional study

Study area- Bell metal industries of Sarthebari, Assam

Inclusion criteria- Employees of bell metal industry in the age group of 20-55

Exclusion criteria- Employees of bell metal industry who are not willing to participatein this study and who have history of Diabetes Mellitus and hypertension prior to joining in the bell metal industries.

Sampling method- Probability sample, Random sampling. The bell metal industries are scattered in various villages over and above the Sarthebari town. The distribution is as follows-

Sarthebari town- 183

Namsala $\quad-53$

Karakuchi $\quad-26$

Gumura $\quad-57$

Lasima $\quad-19$

Amrikhowa - 12

As there are 5/6 employees per industry, therefore a total of 32 industries were to be selected randomly to get the required sample size. So it was decided to select 17 industries from Sarthebari town, 5 from Namsala, 2 from Karakuchi, 5 from Gumura, 2 from Lasima and 1 from Amrikhowa proportionately.

From these cottage industries a total of 163 employees were interviewed and data collected on age, duration of working, drug history and family history. After taking informed consent these willing participants were assessed for pulse, height, weight, blood pressure and random blood sugar. Random blood sugar was measured by glucometer. After taking proper aseptic antiseptic precaution left ring finger was pricked by preset lancing device and about $0.5 \mu$ l blood was collected by automated blood glucose monitoring system.

Statistical analysis

Data was analyzed using Microsoft excel and SPSS software.

\section{Result}

In the table 1(a), mean RBS against age group is shown and it has been found that mean RBS in the age group below 20 yrs is $89 \mathrm{mg} / \mathrm{dl}$ and mean RBS in the age group 20-40 yrs is

Volume 10 Issue 6, June 2021 www.ijsr.net 


\section{International Journal of Science and Research (IJSR)

$103 \mathrm{mg} / \mathrm{dl}$, in the age group of $41-60 \mathrm{yrs}$ it is $135 \mathrm{mg} / \mathrm{dl}$ and in the age group of $60+$ it is $86 \mathrm{mg} / \mathrm{dl}$.

Using Pearson's correlation coefficient (in table1b) it has been found that in our study, age of the employees is not strongly correlated with RBS.

Table 2(a) shows RBS against work duration. Again using Pearson's correlation efficient (table 2b), it is found that RBS is not strongly associated with work duration. Table 3 shows distribution of people of different age groups in different RBS level categories. The table 4 is based on table 3 and $\mathrm{P}$ value for the chi square corresponding to the table 4 is 0.38990354 which is much greater than .05 level of significance. Hence it is statistically insignificant. Thus it can be accepted that age is insignificant of glycemic status.

Again the sample proportion $=5 / 163=0.0307$. (considering the normal range of RBS to be $<200 \mathrm{mg} / \mathrm{dl}$ )

\section{Population proportion $=.059$ (for rural population)}

Using $\mathrm{z}$ test for proportion we have $\mathrm{z}=-1.53341$ and it may be concluded that there is no significant prevalence $(\mathrm{p}=.063)$ of hyperglycemia among the employees of the bell metal industries of Sarthebari.

Table 1 (a): Table showing the vitals against age groups:

\begin{tabular}{|c|c|c|c|c|}
\hline Parameter & $\begin{array}{c}\text { No. of } \\
\text { Persons (\%) }\end{array}$ & $\begin{array}{c}\text { Mean } \\
\text { RBS }\end{array}$ & $\begin{array}{c}\text { Mean } \\
\text { systolic BP }\end{array}$ & $\begin{array}{c}\text { Mean } \\
\text { diastolic BP }\end{array}$ \\
\hline$<20$ Yrs & $5(3.06 \%)$ & $89 \mathrm{mg} / \mathrm{dl}$ & 120 & 74 \\
\hline $20-40 \mathrm{yrs}$ & $102(62.57 \%)$ & $103 \mathrm{mg} / \mathrm{dl}$ & 123 & 81.5 \\
\hline $41-60 \mathrm{yrs}$ & $48(29.44 \%)$ & $118 \mathrm{mg} / \mathrm{dl}$ & 135 & 85.9 \\
\hline $60+$ & $8(4.9 \%)$ & $86 \mathrm{mg} / \mathrm{dl}$ & 154 & 100 \\
\hline Total & $163(100 \%)$ & $106 \mathrm{mg} / \mathrm{dl}$ & 128 & 84 \\
\hline
\end{tabular}

Table 1(b): Table showing the correlations (pearson's) between the variables

\begin{tabular}{|c|c|c|}
\hline \multicolumn{3}{|c|}{ between the variables } \\
\hline & Age & RBS \\
\hline Age & 1 & .166 \\
\hline RBS & .166 & 1 \\
\hline
\end{tabular}

Table 2(a): Table showing RBS against work duration

\begin{tabular}{|c|c|c|}
\hline Parameter & No. of persons (\%) & Mean RBS \\
\hline 1-5yrs & $31(19.01 \%)$ & 100 \\
\hline 6-10yrs & $41(25.15 \%)$ & 101 \\
\hline $11-15 y r s$ & $23(14.11 \%)$ & 109 \\
\hline $16-20 y r s$ & $30(18.4 \%)$ & 110 \\
\hline $21+$ & $38(23.31 \%)$ & 108 \\
\hline
\end{tabular}

Table 2(b): Table showing correlation between RBS and work duration

\begin{tabular}{|c|c|c|}
\hline & RBS & Duration of work \\
\hline RBS & 1 & .134 \\
\hline duration of work & .134 & 1 \\
\hline
\end{tabular}

Table 3: Detail Data of random blood sugar level against Age

\begin{tabular}{|c|c|c|c|c|c|c|}
\hline \multirow{2}{*}{} & \multicolumn{2}{|c|}{$<140 \mathrm{mg} / \mathrm{dl}$} & \multicolumn{1}{c|}{$140-199 \mathrm{mg} / \mathrm{dl}$} & \multicolumn{2}{c|}{$>200 \mathrm{mg} / \mathrm{dl}$} \\
\cline { 2 - 7 } & Count & $\%$ & Count & $\%$ & Count & $\%$ \\
\hline$<20 \mathrm{yrs}$ & 5 & $100 \%$ & 0 & 0 & 0 & 0 \\
\hline $20-40 \mathrm{yrs}$ & 96 & $94.11 \%$ & 4 & $3.92 \%$ & 2 & $1.96 \%$ \\
\hline $41-60 \mathrm{yrs}$ & 40 & $83.33 \%$ & 6 & $12.5 \%$ & 2 & $4.16 \%$ \\
\hline $60+$ & 8 & $100 \%$ & 0 & 0 & 0 & 0 \\
\hline
\end{tabular}

\begin{tabular}{|l|l|l|l|l|l|l|}
\hline Total & 149 & $91.41 \%$ & 10 & $6.13 \%$ & 4 & $2.45 \%$ \\
\hline
\end{tabular}

Table 4: Observed Frequency

\begin{tabular}{|c|c|c|c|c|}
\hline Age & Normal & Intermed & Glycemic & Total \\
\hline$<20$ & 5 & 0 & 0 & 5 \\
\hline $20-40$ & 96 & 4 & 2 & 102 \\
\hline $41-60$ & 40 & 6 & 2 & 48 \\
\hline $60+$ & 8 & 0 & 0 & 8 \\
\hline Total & 149 & 10 & 4 & 163 \\
\hline
\end{tabular}

\section{Discussion}

Noise is an environmental pollutant and though the major impact of noise is on hearing yet various studies opined that noise may produce adverse effects in other systems also. Noise can cause release of different stress hormones (e.g. corticotropin releasing hormone: $\mathrm{CRH}$; adrenocorticotropic hormone ACTH) especially in sleeping persons during the vagotropic night/ early morning phase (4)During the waking period whether noise can increase cortisol level or not is a matter of research. The aim of present study was to find out prevalence of hyperglycemia, if present, in workers of bell metal industries of Sarthebari because it might lead to generation of hypothesis that exposure to noise chronically in these bell metal industries may be a factor for increased blood sugar level. Our study did not include female subjects as all the employees of bell metal industries were male. All the subjects were non vegetarian. In the present study the noise level of the bell metal industries were measured using decibelmeter and the maximum level of noise was found to be in the range of $110 \mathrm{dBA}$ to $117 \mathrm{dBA}$. Height, weight, pulse, blood pressure and random blood sugar of the subjects were measured. Then statistical analysis was done and the results indicate that age is not strongly associated with blood sugar level and there is no significant prevalence of hyperglycemia in the employees of bell metal industry. This finding is not supporting the findings of other studies like a study conducted by L H Ding et al. in 670 workers in an automobile manufacturing company concluded that compared with the control group, there were significant differences in systolic blood pressure, diastolic blood pressure and blood glucose in the contact $\operatorname{group}(\mathrm{p}<0.05)$. Another study conducted by Ta-Yuan et al. commented "an increased relative risk for hyperglycaemia of 1.80 (95\% confidence interval [C.I.]1.04,3.10) was found among subjects exposed to $\geq 85$ A-weighted decibels (dBA) compared with those exposed to $<70 \mathrm{dBA}$ ".

In our study significant prevalence of hyperglycemia is not found despite chronic exposure to noise and this observation may be related to the strenuous exercise done by the employees of bell metal industries regularly and it is a known fact that exercise has blood glucose lowering effect.

One of the major limitation of this study is that we could not collect fasting blood samples and hence we could not estimate fasting blood sugar level. To comment on prevalence of hyperglycemia estimation of fasting and post prandial blood sugar level is more relevant. 


\section{Conclusion}

Noise adversely affects the health. Over and above the hearing system, other systems are also influenced by health. Many researchers have found correlation between noise and diabetes. Though in our study, it has been observed that there is no prevalence of hyperglycemia in employees of bell metal industries of sarthebari yet it needs further evaluation , further research in this field. Proper evidence based facts may protect the health of the employees by guiding them to take precautionary measures to reduce the noise exposure and also by encouraging them to adopt healthy life style.

\section{Funding}

This study is self funded.

\section{Acknowledgements}

We are grateful to all the members of Sarthebari kohar sangha and all the employees of bell metal industries of Sarthebari for their whole hearted cooperation in this study. Dr Padmaja Barua, Dr Jolly Bhattacharjya, Dr Smriti Pathak Department of Physiology, Gauhati Medical College, Guwahati

\section{References}

[1] Münzel T, Sørensen M, Schmidt F, Schmidt E, Steven S, Kröller-Schön S, Daiber A. The Adverse Effects of Environmental Noise Exposure on Oxidative Stress and Cardiovascular Risk. Antioxid Redox Signal. 2018 Mar 20;28(9):873-908. doi:

[2] 10.1089/ars.2017.7118. PMID: 29350061; PMCID: PMC5898791.

[3] Chang TY, Yu TY, Liu CS, Young LH, Bao BY. Occupational noise exposure and its association with incident hyperglycaemia: a retrospective cohort study. Sci Rep. 2020 May 22;10(1):8584. doi: 10.1038/s41598-020-65646-1. PMID: 32444842; PMCID: PMC7244742.

[4] Ding LH, Sun RB, Wu K, Wu JB, Zheng JR, Yuan ZP, Mei LY. [Study on the effects of noise on hypertension and hyperglycemia among occupational workers]. Zhonghua Lao Dong Wei Sheng Zhi Ye Bing Za Zhi. 2020 Jan 20;38(1):32-36. Chinese. doi: 10.3760/cma.j.issn.1001-9391.2020.01.007. PMID: 32062893.

[5] Spreng M. Possible health effects of noise induced cortisol increase. Noise Health. 2000;2(7):59-64. PMID: 12689472. 